Bol. Acad. peru. leng. 62. 2017 (19-40)

\title{
El proyecto existencial de César Moro: hacerse un nuevo hombre
}

\author{
The existential project of Cesar Moro: \\ make yourself a new man \\ DANIEL LEFORT \\ Universidad de la Sorbona-París IV
}

\section{Resumen:}

César Moro es un caso único en el campo de las letras y del arte del siglo XX por su trayectoria de vida. Primero por la manera de transformarse en una nueva persona por medio de una serie de renuncias conscientes $y$ voluntarias a las características que determinan la condición habitual del ser humano: su nombre, su lugar de nacimiento, su lengua materna. Así, fueron el resultado de una elección propia la adopción de un nuevo nombre, su partida a Europa, su expresión poética en francés. A eso se sumó el descubrimiento del arte y de su homosexualidad para darle un perfil totalmente fuera de lo común. Pero estos rasgos se convirtieron en elementos de construcción de su nuevo ser cuando se encontró en París con el grupo surrealista y conoció los ideales del comunismo. Surrealismo y comunismo le dieron los conceptos que esperaba, el primero sobre la liberación de la persona a través del amor y la poesía, el 
segundo sobre la liberación del hombre por la revolución. Ese ideal del nuevo hombre, diseñado por y para él mismo, no estuvo exento de contradicciones o de pulsiones fuera de control que motivaron, por ejemplo, sus retornos a Lima o su regreso temporario al idioma español. Son estos desgarramientos que dan a la figura de Moro y a su obra su sentido profundamente humano y su valor universal.

\section{Abstract:}

For his lifestyle, Cesar Moro is a unique case in the field of arts and literature in the twentieth century. This is because of the way he transforms himself into a new person by means of a series of conscious and voluntary resignations to the characteristics that determine the usual condition of a human being: his name, his place of birth, his mother tongue. Thus, they were the result of his own choice to adopt a new name, his departure to Europe, his poetic expression in French. Added to all that, he discovered art and his homosexuality giving him a completely out of the ordinary profile. But these traits became construction elements to build his new being when he met in Paris with the Surrealist group and the ideals of Communism. Surrealism and Communism gave him the concepts that he hoped for. The first on the person liberation through love and poetry, the second on the man liberation through revolution. That ideal of the new man, designed by and for himself, was not exempt from contradictions or drives out of control that had led, for example, his returns to Lima or his temporary return to the Spanish language. These rifts 
give a deeply human sense and his universal value to the figure of Moro and his work.

Palabras clave: César Moro, arte, surrealismo.

Keywords: Cesar Moro, art, Surrealism.

Recibido: 24/09/2016

Aceptado: 15/01/2017

\section{Introducción: un hapax poético y humano}

Al final de uno de sus numerosos artículos sobre César Moro, Emilio Adolfo Westphalen escribe esa frase que, en su tiempo, me llamó poderosamente la atención: «No creo que vuelva a conocer a otra persona como él». Hecha cuando rozaba los ochenta años, esta confidencia, subrayando el carácter único de la persona y de la personalidad de su amigo César Moro, era tan perentoria como definitiva. Y, en efecto, parecen incomparables tanto su obra de poeta y de pintor como su actitud frente a la vida, su desprendimiento de todos los hábitos, prejuicios y comportamientos sociales condicionados, su alta exigencia moral, o más bien ética, en todos los aspectos de la actividad artística - la suya y la de los otros-, su dedicación en cuerpo y alma a lo que representa para él la Poesía: la libertad, el amor, la revolución. Como Gaëlle Hourdin lo define en su brillante tesis doctoral sobre la poética de Moro, él es un hapax - es decir, una sola voz registrada una sola vez- en el campo poético peruano. Ella caracteriza su obra por su singularidad y su marginalidad a raíz de su elección del 
francés como idioma y del surrealismo como estética para su expresión poética, lo que no tiene comparación alguna entre los poetas del Perú. Pero esta singularidad y marginalidad no corresponden solamente a su obra, sino a toda su trayectoria vital. Por eso me parece pertinente extender la noción de hapax más allá de su significado en los dominios de la lingüística o de la crítica textual —más allá también del campo semántico del hapax existencial definido por el filósofo Vladimir Jankélévitch y desarrollado por Michel Onfray como evento único en una vida- para proponer la idea de hapax humano que César Moro ilustra de manera ejemplar tanto con sus renuncias como a través de sus convicciones ideológicas, morales y poéticas.

Mi propósito es mostrar -y si es posible demostrar- que César Moro tuvo muy temprano el deseo de convertirse en otro hombre, pasando por un proceso fuera de lo común que consistió primero en una serie de renuncias - a su nombre, a su país, a su lengua- o mejor dicho en una serie de rechazos clara y conscientemente asumidos para de-construir su personalidad socialmente determinada, recibida de manera pasiva a su nacimiento $y$, segundo, en la construcción voluntaria de un nuevo hombre por la elección libre de su lugar y de su forma de vida, además de sus principios de acción y de reflexión. Así él va a cambiar su estatuto de hijo de la pequeña burguesía limeña por el de artista y luego por el de Poeta, pero en una forma totalmente individualista, centrada en su ego, que le dotará de un carisma excepcional y, al mismo tiempo, lo apartará del mundo social comúnmente compartido. Este proceso no estuvo exento, como toda empresa humana, de 
contradicciones y fracasos que lo afectaron profundamente, sin alterar la dimensión casi heroica de su aventura espiritual y existencial de poeta, que podemos comparar a la de Rimbaud o de Mallarmé.

\section{I}

A pesar de la escasez de los datos que tenemos sobre la infancia y la adolescencia de Moro, son suficientes para darnos la certeza de que él reveló temprano su personalidad rebelde en el ámbito encartonado y almidonado que era el de su familia. Una familia burguesa limeña, es cierto, procedente de raíces hispánicas entre Cataluña y Aragón por el lado materno, y oriunda de las ciudades de Ica — por su padre- y de Tarma — por su madre-, con un abuelo director del Parque Zoológico y un padre médico. Pero se trata de una familia un poco decaída, ya que el padre falleció cuando el futuro César Moro tenía tres años y, siendo toda su vida médico de los pobres, dejó pocos bienes para su mujer, su hermana y sus cuatro hijos de poca edad. La familia cambia por lo menos una vez de casa y siempre para reservar una parte al arrendamiento y tener así algo más de dinero. Entre los recuerdos infantiles más gratos de Moro está el de sus visitas al zoológico de la mano de su abuelo en uno de sus primeros poemas, de paseos en los brazos de su niñera frente a la fuente de Neptuno en el parque del mismo nombre, y de una visita al antiguo Museo Nacional: son los recuerdos de un hijo de familia mediana, bien educada pero no abundante en recursos económicos. Aunque no faltan los recuerdos malos. En su Journal (1934-1936), escribe: "La seule chambre de la 
maison où j'ai vécu qui a pour moi une signification, qui vit, c'est la toute dernière, celle de laquelle on a fait un débarras. Je hais les autres où se trouve l'image du Sacré-Cœur / La única pieza donde viví que tiene una significación para mí es la última, aquella que hicieron de buhardilla. Detesto las otras donde se encuentra la imagen del Sagrado Corazón», imagen que reafirma el conformismo burgués de la familia en materia de religión. En un poema, expresa su odio a los domingos, días de misa y de encuentro familiar por excelencia. También expresará, apenas alejado del Perú en septiembre de 1925, la complejidad de sus relaciones familiares con un sentimiento general de sufrimiento tanto por el amor exclusivo de su madre ("Qué cruel mi madre de haberme besado tanto y tan dulcemente») como por el odio a sus hermanos («Por qué yo debí soportar a mis hermanos mayores»). No es extraño entonces ver que, entre conformismo familiar y odio, el joven Alfredo Quíspez Asín — su nombre de nacimiento- adoptó tempranamente una actitud de rebeldía y de disconformidad que iba a traducirse en una escolaridad agitada hasta hacerse echar por indisciplina por los padres jesuitas del Colegio Inmaculada - colegio privado tradicional para los hijos de la burguesía limeña- después de tres años de pocos estudios aparte de una materia bien recordada: el idioma francés.

No se sabe cómo de niño - y más tarde de adolescente y de joven adulto-Alfredo se sentía en el medio de la sociedad limeña donde las diferencias sociales tenían mucho que ver con el color de la piel y los rasgos faciales. André Coyné evoca al abuelo paterno de Moro, Hipólito Quíspez, como «mestizo, comerciante de 
categoría en la plaza de Ica». Y en su artículo «A propósito de la pintura en el Perú», Moro escribe: «veo, como cualquiera puede verlo, su explotación [al indio] en mayor o menor grado, al mismo título que los mestizos que poblamos la costa». Esa forma inclusiva de evocar a los mestizos es la única en sus escritos, por lo que se sabe, y debemos notar que los rasgos físicos de Moro parecen acercarle más al perfil del pequeño blanco de la ciudad. No obstante, esa indicación no deja de llamar la atención de parte de un joven rebelde que desprecia a toda la sociedad.

No se sabe exactamente tampoco cuándo Moro descubrió otra faceta de su personalidad que iba a alejarlo de la conformidad social: su homosexualidad. André Coyné menciona que fue iniciado de joven por un empleado de la casa, lo que pone al revés la experiencia más común de los hijos de la burguesía que iban a iniciarse al sexo en el lecho de las sirvientas. Lo que queda claro es que asumió su orientación sexual al parecer con soltura y que esta fue parte constitutiva del nuevo hombre al cual aspiraba.

La forma más llamativa de su alejamiento del molde social se nota en su orientación temprana hacia el arte. Ya tenía en casa el ejemplo de su hermano Carlos -el segundo de la hermandad que tenía tres años más que él- «destinado a ser un gran pintor». El joven Carlos empezó a estudiar pintura con el maestro Teófilo Castillo y siguió cursos en la recién creada Escuela Nacional de Bellas Artes, pero estaba poco conforme con los criterios artísticos del maestro Castillo y de la ENBA, así que su hermano menor, Alfredo, se relacionó más directamente con las tendencias 
vanguardistas del simbolismo y del decadentismo. A los dieciséis, empieza a frecuentar las tertulias dominicales de José María Eguren en su casa de Barranco. Allí descubre la obra poética y plástica del único poeta simbolista de América -el que Moro considerará como «el Poeta por excelencia»- y, también, en libros y revistas que Eguren recibía de Europa y toda América, las últimas corrientes literarias y artísticas vigentes, casi desconocidas o - en el peor de los casos- despreciadas en el Perú de aquella época fuera de dos círculos: la revista Amauta de Mariátegui y las tertulias de Eguren. Pronto se dedica a sus primeros ensayos, ya que su primer dibujo está fechado en 1921 —tiene dieciocho años-. Además, «en cartas de 1922 dice realizar dibujos y acuarelas» y que también en estos momentos «comenzó a ejercer como ilustrador de libros». Él tiene una consciencia muy clara del carácter críptico y de protesta que conllevan sus obras. Escribe: «Para mí, [mis dibujos] son como interrogaciones, como protestas contra la vida y contra todo [...]. Más contento estoy cuando aparentemente más incoherente es uno de mis dibujos. Un dibujo no es una confesión. Al contrario, yo mismo no sabría explicar un dibujo». Aquí vemos que a su rebeldía adolescente contra la sociedad se agrega la elección de una expresión artística en contra de los criterios académicos vigentes. Moro se ubica directamente del lado de la modernidad, con el mismo gusto que los simbolistas en general y Eguren en particular por la oscuridad del arte. Pero, al mismo tiempo, busca el reconocimiento público, trata de exponer sus obras. Fernando Villegas escribe: «A César Moro, le fue difícil dar a conocer su obra en este medio, pues su juventud 
y su modernidad fueron un obstáculo que lo mantuvo alejado de las salas de exposición de la época. En este sentido, fue reiterativo el interés del artista por exhibir sus dibujos». Eso lleva a Moro hasta un punto de ruptura entre su consciencia de ser artista y el escepticismo de su entorno. Escribe a su hermano el 29 de noviembre de 1924: "Cuando tú [Carlos] te fuiste [en 1921 a España] era yo un temperamento artístico. Sólo que ahora soy un artista hecho y derecho, pese a los estúpidos pesimismos de quienes me creen un chico».

Esa consciencia plena de sí mismo, adquirida en muy pocos años al fin de su adolescencia, muestra a un hombre lleno de certezas sobre lo que es y lo que quiere ser. Ya tiene dos anhelos: salir del país y cambiar de nombre. Escribe el 4 de marzo de 1922: «No veo las horas de salir de Lima». El primero no es totalmente original: dejar un país aislado de los centros internacionales del arte y de la vida intelectual —que se sitúan en Europa y especialmente en París- es la aspiración de muchos jóvenes escritores y artistas de América Latina de la época. Pero en el caso de Moro, dejar su país es dejar al niño y al adolescente que fue, al pequeño Alfredo Quíspez Asín. Escribe a Carlos el 6 de septiembre de 1923:

La cuestión esa del nombre ha sido siempre para mí una tortura y naturalmente he tratado de sacudírmela. Cuando llegó tu carta hace cuatro o cinco días, ya tenía - después de mucho pensar y no encontrar- ya tenía un nombre: CÉSAR MORO [...] No sé qué te parecerá el nombre: a mí me suena bien, es eufónico. Conste que no es de mi invención, y esto me friega, lo encontré en un libro de Gómez de la Serna. Felizmente no es un personaje importante ni interesante. Lo más que le sucede es 
tener un caballo de frisa que gana el derby en Londres. Además, es un burgués. Por supuesto cuando me escribas pondrás en el sobre: Sr. Don César Moro.

Esta carta incita a varias observaciones. Primero, no se trata de la búsqueda sencilla de un seudónimo, un nombre de artista, sino de la necesidad angustiosa de tener una nueva identidad, una identidad elegida libre y personalmente. Por eso se molesta cuando se presenta la revelación, la evidencia del nombre, no por creación sui generis, sino por encontrarlo en las páginas del libro de un novelista. Moro usa todos los atenuantes para conservar la originalidad del descubrimiento. Pero lo convence el carácter poético del nombre que «suena bien», corto y sonoro, bien balanceado entre sus cuatro sílabas —dos más dos-. Además, podemos agregar que se trata de un nombre imperial y de un apellido imponente, pensando en el «Moro de Venecia», el Otelo de Shakespeare, asociación de personajes de poder terrible, casi mitológicos, que auguran la fama anhelada. Y la mención final, orgullosa, debe tomarse al pie de la letra: César Moro se llamará César para toda su familia y hará todo lo posible para cambiar su estado civil en los registros oficiales del Perú y afuera, incluso quince años después en México, cuando logrará tener un documento oficial declarando su identidad como César Moro Mas, hijo de Jesús Moro (jsic!) y de María Estela Mas. Westphalen escribe: «Moro fue siempre César Moro conforme constaba en su libreta electoral y demás documentos». Moro impuso a todo su entorno la diferencia entre llamarse y ser (Yo me llamaba Alfredo pero soy César Moro). 
Con el cambio de nombre a principios de septiembre de 1923 y la salida del país a fines de agosto de 1925, culmina el rechazo de la figura del pequeño burgués peruano, condicionado por su nacimiento a vivir en tal lugar - Lima- y de tal forma - en familia-. Liberarse de los lazos y de las determinaciones sociales va a permitir al nuevo hombre, que él definió ya como artista, salir de su piel como la serpiente haciendo su muda, pero falta todavía darle su color y su lustre definitivos. Moro llega a París con varias opciones. Tiene la idea de perfeccionarse en el arte de la danza, también de exponer los cuadros que trajo en su equipaje $y$, tal vez, de continuar su obra poética incipiente, ya que publicó, algunos meses antes de su salida, tres poemas en la revista El Norte de Trujillo. Lo cierto es su vocación artística, el resto queda por definir.

\section{II}

Desprenderse de su idioma natal fue el resultado de su instalación en Francia y luego de su incorporación en los medios intelectuales y artísticos de París. Si bien continúa escribiendo poemas en español hasta mediados de 1928, el poema "Arcachon. 15 septiembre 1928» contiene varias palabras y una frase en francés, y dos poemas de 1927, «Oráculo» y «Scarabée ou Maman», llevan citas en francés de Louis Aragon y Paul Éluard. Los primeros textos conocidos de Moro en francés están fechados en 1930 y muestran un dominio sorprendente del idioma. Es decir que en menos de cinco años alcanzó un manejo de la 
lengua francesa que le permitió ubicarse a la altura de los grandes poetas de la vanguardia. A partir de esta época, el francés será su idioma poético por excelencia, incluso en sus cartas a sus amigos como Emilio Adolfo Westphalen.

El encuentro de Moro con el surrealismo tiene valor de revelación. Es probable que ya en Lima Moro haya leído textos de los surrealistas y admirado reproducciones de sus obras plásticas: en 1925, el grupo estaba constituido alrededor de André Breton sobre la base conceptual del Manifiesto del surrealismo publicado en 1924. Pero cuando él se acerca al grupo, probablemente en los años 1927-1929, el surrealismo está en su edad de oro, 1927-1929 es la época de la publicación de obras capitales: Nadja de Breton, Traité du style de Aragon, Le Grand Jeu de Benjamin Péret, Capitale de la douleur y L'amour la poésie de Paul Éluard, La liberté ou l'amour de Robert Desnos. Las revistas La Révolution surréaliste - hasta 1929- y Le Surréalisme au service de la révolution - a partir de 1930 - le dan una visión cabal de las producciones y de los debates del grupo acerca de unas ideas claves que Breton trata de constituir con su carisma y mantener en la forma de un conjunto coherente destinado a «transformar el mundo», según Marx, y "cambiar la vida», según Rimbaud. Lo más llamativo es que todos los conceptos que Moro tenía sobre el arte y la vida y que no podía desarrollar en Lima son los mismos que los surrealistas promueven en un ámbito parisino mucho más receptivo a la modernidad. Él podía, por ejemplo, suscribir sin reticencia la Déclaration du 27 janvier 1925, firmada por el grupo y que dice (traducido del francés): 
«No tenemos nada que ver con la literatura pero somos capaces de usarla como todo el mundo».

«El surrealismo no es un medio de expresión nuevo o más fácil, tampoco una metafísica de la poesía; es un medio de liberación total del espíritu».

«Estamos bien decididos a hacer la Revolución». «Somos especialistas de la Rebelión».

En realidad, Moro descubre lo que deseaba tanto en Lima: la libertad del comportamiento, la liberación del deseo, la consagración del amor y la poesía. Es decir que con el surrealismo Moro se siente como un pez en el agua. Comparte sus ideales, sus metas y sus protestas. Cuando escriba sobre el movimiento surrealista, siempre será con imágenes violentas y desgarradoras: «El surrealismo es el cordón que une la bomba de dinamita con el fuego para hacer volar la montaña. La cita de las tormentas portadoras del rayo y de la lluvia de fuego» (nota introductora de mayo de 1938 a las traducciones de poemas surrealistas franceses por Moro en la revista Poesía, México).

Lo mismo con la poesía surrealista: «Aquí todo existe de otro modo, la poesía [...] es la guarida de las bestias feroces, el advenimiento de la era antropófaga, la selección de los peores instintos de asesinato, de violación, de incesto» (Los anteojos de azufre, 1934).

Pero además del poder destructor del mundo antiguo que Moro alaba en sus textos más provocativos, lo que encuentra en el grupo son los paradigmas de su propio ser. Si bien hace reverencia a Picabia y Picasso y se codea con Aragon y Péret, sus dos figuras tutelares son André Breton y Paul Éluard. A cada uno de ellos entrega el manuscrito de sus primeros poemarios en 
francés en 1932, poemarios que desaparecieron luego. A los dos dedica el poemario inédito que publicará André Coyné bajo el título Ces poèmes...:

\author{
Estos poemas y su sombra \\ consecuente y su luz \\ consecuente están dedicados \\ a André Breton \\ a Paul Éluard \\ con la infinita admiración de
}

César Moro

Cada uno de ellos recibe el homenaje de un poema extenso. En el barco que lo trae de vuelta al Perú en 1933, escribe una vez más como epígrafe del poema «Où le sang manifeste le désir»: «De tout temps à André Breton et Paul Éluard» (Desde siempre a André Breton y Paul Éluard). Con André Breton y su personalidad solar encontró la exigencia superior de la libertad y la devoción intransigente a la poesía. Con Éluard, quien a su misma edad eligió su nombre de poeta en contra del estado civil (Eugène Grindel), comparte una fraternidad en la simbiosis entre amor y poesía (L'amour la poésie, 1929), y el sentimiento desgarrador del dolor en el amor (Capitale de la douleur, 1926) así como la aspiración a La vie immédiate (1932).

Moro se acerca al grupo surrealista en pleno auge del debate sobre la forma cómo articular la revolución surrealista y la revolución comunista. Lo cierto es que Moro va a asumir las posiciones de Breton por lo menos hasta fines de los años treinta, atravesando conflictos internos y exclusiones, sin vacilar en su fidelidad. En 1933, dimite de la Asociación de Escritores y Artistas 
Revolucionarios (SASDLR) cuando echan a Breton. No hay duda de que su compromiso político es importante. Cuando regresa a Perú una de sus actividades será participar muy activamente en la redacción del Boletín de la CADRE, una asociación de apoyo a los republicanos españoles en plena guerra civil en España mientras el gobierno militar de Sánchez Cerro apoya al general Franco. No lo hizo sin riesgos, ya que fue por persecución política que debió exiliarse en México en 1938. Allá, acompaña a Breton en su visita a Trotski en Cuernavaca. Por supuesto, se pone en contra del estalinismo y especialmente del pacto germano-soviético — «esta saña castradora en que el fascio y el martillo llegan a fraternizar»-y por consecuencia rompe con Éluard, que se volvió estalinista como Aragon. En arte, su posición política se traduce por el rechazo al realismo socialista — «el arte para imbéciles»-. Aún si su compromiso político se refleja muy poco en su poesía - solo un poema fechado «Pâques, 27 mars 1932» está consagrado a la alabanza del pueblo y del proletariado: «Tout est pour vous ô peuple» / «Todo está para vosotros oh pueblo»- es una constante que confirma su adhesión total al surrealismo de Breton y a la position politique $d u$ surréalisme. Recordemos la visión del nuevo hombre comunista que imagina León Trotski en 1924:

El hombre será mucho más fuerte, mucho más perspicaz, mucho más fino. Su cuerpo será más armonioso, sus movimientos más rítmicos, su voz más musical. El promedio humano se alzará al nivel de Aristóteles, de Goethe, de Marx. Y arriba de esta cresta de montañas, se alzarán nuevas cumbres. 
A pesar de su lirismo hiperbólico, esta visión encaja perfectamente con el anhelo revolucionario que moviliza a los surrealistas y a Moro entre ellos.

Así que, llegando a la «década prodigiosa» de los años treinta, entre los últimos tres años de su estadía en París, los cinco años de su regreso a Perú y los primeros años de su exilio a México, César Moro logra construir su personalidad. Parece desnudarse por completo, sacando de sus espaldas los viejos hábitos del nombre, de la sociedad limeña, del país y de la lengua para entrar en su nuevo ser como artista surrealista, dedicado a la pintura y la poesía, seguro de sus convicciones filosóficas y políticas, adquiridas gracias a dos sistemas de pensamiento libertadores: el surrealismo como liberación del individuo y el comunismo como liberación del hombre.

\section{III}

El concepto que Moro tiene ahora del hombre nuevo conlleva unas características radicalmente opuestas al patrón sociocultural que había heredado, «el triste patrimonio de la mayoría gris y espesa de los intelectuales del Perú y de los que sin profesar de intelectuales tienen una opinión». Él pone énfasis en el rechazo al trabajo, valor burgués por excelencia. Si bien lo expresa en su poema "Abajo el trabajo», lo practicará en forma permanente, sobreviviendo gracias a pequeños empleos precarios, no sin cierta desenvoltura (en México, regala libros a los estudiantes cuando está de librero o hace pasar gente sin dinero al cine donde recibe al público. Julio Ortega cuenta 
que «César Moro trabajó en la boletería del palacio de Bellas Artes de México. Dicen que Moro reducía el precio de las entradas a los obreros»). Paralelamente, hace una gran valoración de la locura, especialmente gracias a sus actividades en el museo del hospital psiquiátrico Larco Herrera de Lima en los años treinta y cincuenta. Hay testimonio de que, ya antes de 1925, "César Moro junto con Enrique Casterot y Jorge Seoane frecuentaban el manicomio de Lima, conocido como el asilo Víctor Larco Herrera, donde el doctor Valdizán les habló extensamente sobre la vida, sobre los individuos vistos a través del psicoanálisis (carta de Moro)». "Valdizán se había hecho amigo del grupo Los Locos, cuyos integrantes invitaba a tomar el té en el Asilo de la Magdalena. De ahí surgieron los recitales para algunos internos donde [...] participaron Casterot y César Moro, y durante estos eventos muchos de ellos tomaban apuntes». Escribe Moro en 1934: «la sola poesía entre nosotros está en la producción borrascosa y esporádica: textos, objetos, cuadros de los alienados, en el Hospital Larco Herrera» («Los anteojos de azufre») y en 1938-1939:

No renunciaré jamás [...] a

la pérdida de las facultades y la adquisición de la demencia [...]

El grandioso crepúsculo boreal del pensamiento esquizofrénico

La sublime interpretación delirante de la realidad

No renunciaré jamás al lujo primordial de tus caídas vertiginosas oh locura de diamante

(«A vista perdida») 
Al final de su estadía en México, Moro traduce al español uno de los textos más extraños y conmovedores sobre la experiencia de la locura. Se trata de En bas (Abajo), de Leonora Carrington, que describe su caída en la locura como una bajada en el infierno. De este texto, Moro dice significativamente que es el relato de su paso por «el mundo terrible, y cuán lleno de atracción, de la locura». No parece que Moro se haya deslizado por este camino, aún si repite "Je suis fou / Estoy loco» en varios poemas, especialmente en este verso excéntrico: "Je suis fou comme un bouton de manchette / Estoy loco como un gemelo». Pero sí se entrega a una locura terrible, la del amor y particularmente a la de su aventura pasional con Antonio en México. Antonio, destinatario del poemario La tortuga ecuestre y de Las cartas, y sujeto de Lettre d'amour y de los poemas que componen todos juntos lo que André Coyné ha llamado «El ciclo de Antonio».

Siendo el amor pasional el tema general de este congreso, no voy a extenderme sobre el asunto sino para subrayar la relación orgánica que Moro trama entre amor y locura como pilares de sus razones de ser: la liberación individual y la liberación del hombre a través de la imaginación y del sueño. Por eso, sintetiza en una fórmula única esas equivalencias: «En el sueño y por el sueño deben resolverse los problemas capitales del hombre: el amor, la locura, es decir, la poesía, la revolución».

Así tenemos al nuevo hombre soñado por Moro: un poeta que se expresa tanto por la palabra escrita como por el arte plástico, que incorpora en su modo de ser la potencia de la imaginación y del sueño, sea 
individualmente -reconociendo por ejemplo el valor de las producciones de los alienados- o colectivamente -a través de la acción revolucionaria-. Supone una alta consciencia de sí mismo y un rigor moral e intelectual que no permiten aflojar ni hacer compromisos con la realidad y la sociedad. Escribe: "Au fond, je suis un mystique sans discipline religieuse / En el fondo, soy un místico sin disciplina religiosa».

\section{IV}

Pero conseguir definirse y afirmarse en una forma tan singular no resulta una tarea fácil. Si bien Moro comparte su postura existencial con un pequeño grupo en cada lugar — con Breton, Éluard y los miembros más cercanos a ellos en París, Emilio Adolfo Westphalen en Lima, Xavier Villaurrutia y Agustín Lazo en México-, le lleva más que todo a una soledad casi permanente. Guillermo Sucre lo subraya: «fue un solitario, irrecuperable», y Moro mismo dedica un poema suelto, muy lírico, probablemente de los años 1932-1933, a su propia soledad: "Malédictions puissantes, descendez sur moi / Potentes maldiciones, bajad hacia mí». Y lo lleva sobre todo a un enfrentamiento rabioso y constante con el mundo: «il faudrait tout détruire jusqu'aux cendres, jusqu'à l'ombre, pour ne plus recommencer, pour faire disparaître cette honte que signifie exister ne fût-ce qu'un instant / Habría que destruir todo hasta las cenizas, hasta la sombra, para no empezar de nuevo, para hacer desaparecer esta vergüenza que significa existir, aún un instante» ("À l'occasion du nouvel an», el poema de la negación absoluta). Por eso lo persigue 
una tentación reiterada de suicidio, que lo emparenta con Breton. En 1930, tiene «la convicción profunda de que nada vale lo que vale el suicidio como término, como fin a proponerse»y en 1936: "Car qui ne sait que je ne vis que dans l'espoir du suicide / Quien no sabe que vivo solamente en la esperanza del suicidio». Tentación jamás cumplida. Más allá de todas las renuncias llevadas al extremo y superadas con éxito, más allá de la soledad donde "Le combat spirituel est aussi brutal que la bataille d'hommes» («El combate espiritual es tan brutal como la batalla de hombres»), como dice Rimbaud, el último paso es la muerte. Cuando da la espalda a la muerte, Moro entra en las contradicciones y debilidades que son propias de la condición humana. Así, rechazar a su familia y su país no impide que, en dos oportunidades, motivado por los llamados insistentes de su madre, vuelva al Perú. Adoptar el francés como idioma poético no impide que, cuando vive su pasión amorosa con Antonio en México, regrese al español para escribir los poemas de La tortuga ecuestre y dirigir por la palabra la fuerza torrencial de su amor a su destinatario. Además, la crítica feroz que hace de su país y de su sociedad no impide que escriba unas páginas entre las más hermosas sobre el Perú, su historia prestigiosa y la belleza de sus paisajes. Bastará citar - en lo que se refiere a la historia - un texto — «iografía peruana»- muy inspirado por el libro de Prescott sobre la civilización de los incas, pero lleno de un sentimiento muy auténtico, totalmente imbuido de poesía: «Pienso con fervor en el gran amor de los antiguos peruanos por las piedras», "Viajo de noche hacia el muro de seda». Y para los paisajes, esta visión 
inspirada, caída de su pluma en los últimos tiempos de su vida (15 de agosto de 1955): «Ce n'est pas en vain que je suis né, tandis que des milliers de Péruviens sont encore à naître, au pays consacré au soleil et si près de la vallée de Pachacamac, sur la côte fertile en cultures hautement magiques sous l'envol majestueux du pélican tutélaire / No en vano nací, cuando miles de peruanos quedan por nacer, en el país consagrado al sol y tan cerca del valle de Pachacamac, en la costa fértil en culturas altamente mágicas, bajo el vuelo majestuoso del divino pelícano tutelar».

En el ocaso de su vida, a los cincuenta años, se insinua en él la última contradicción, la afirmación de un amor a la vida que aniquila los impulsos de la muerte que le asaltaban antaño. Concluye un poema corto del 20 de agosto de 1953, «Le sang qui me dénomme» («La sangre que me nombra»), con estos versos: «Et je vis et je chante / Et tout est ivre et la / Vie retrouve son sens / Et je suis libre» / "Y vivo y canto / Y todo está ebrio y la / Vida retoma su sentido / Y soy libre».

Es decir que elegir la vida es un acto de voluntad, una forma dionisiaca de unir la locura (el canto, la ebriedad) y el ejercicio de la libertad. Es un eco a las nuevas convicciones que expresó a Westphalen cuando tenía la intención de regresar al Perú desde México: «Ahora, después de tantos años de haber pensado en el suicidio, sé que amo la vida por la vida misma por el olor a la vida». 


\section{Conclusión}

Podríamos concluir, después de esta breve y apresurada retrospectiva siguiendo el sentido de la vida de Moro, que su proyecto de vida quedó truncado, que fue uno más de los artistas y escritores peruanos fracasados que Mario Vargas Llosa ha analizado de manera clarísima. Él señala a Moro en su ensayo sobre Sebastián Salazar Bondy como «el caso extremo del peruano exiliado». $Y$ es verdad que si medimos la estatura del poeta con la cantidad de publicaciones y exposiciones de sus obras en vida, llegamos a tres poemarios editados, dos en México y uno en Lima en forma confidencial, y cuatro exposiciones colectivas (Bruselas, París, Lima y México) de limitado alcance. Es decir que, a la hora de su muerte en 1956, noventa por ciento de sus poemas quedaban inéditos y la casi totalidad de sus pinturas invisible. Pero el mismo Vargas Llosa escribe: «¿Quién sabe si algún día la literatura del Perú resucitará al otro Moro, el verdadero y magnífico poeta que llevó a su tumba?» Cincuenta años después de la pregunta de Vargas Llosa, milagrosamente, como llega la luz de las estrellas lejanas, vemos que la fama de Moro y su reconocimiento crecen en el Perú y en América Latina -y nacen en Europa - gracias, primero a los esfuerzos poco comunes de André Coyné y a la dedicación de investigadores como Julio Ortega, Américo Ferrari y Ricardo Silva-Santisteban y, ahora, gracias al interés desplegado por los estudiosos y la nueva generación.

Resucitar a Moro ya no es una utopía, pero queda todavía mucho camino por hacer. 